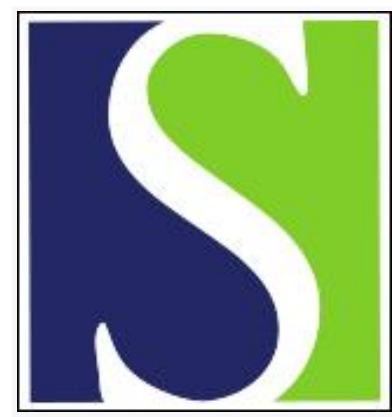

Scand J Work Environ Health 2016;42(2):170-174

https://doi.org/10.5271/sjweh.3546

Published online: 20 Jan 2016, Issue date: 01 Mar 2016

Mid-life job insecurity associated with subjective well-being in old age: results from the population-based MONICA/KORA study

by Barrech A, Baumert J, Emeny RT, Gündel H, Ladwig K-H

Using data from a large scale population-based study with a mean follow-up time of approximately 20 years, this is the first investigation to show that exposure to job insecurity in midlife leaves adverse traces on subjective well-being after retirement. Thus it is in the interest of employees, employers and policy-makers to effectively deal with job insecurity during working life.

Affiliation: Institute of Epidemiology II, Helmholtz Zentrum Mu\&\#776;nchen, German Research Center for Environmental Health, Ingolstädter Landstr. 1, 85764 Neuherberg, Germany. ladwig@helmholtz-muenchen.de

Refers to the following text of the Journal: 2006;32(6):443-462

The following article refers to this text: 2021;47(2):108-116

Key terms: epidemiology; job insecurity; job stressor; MONICA/KORA study; old age; risk factor; stress; subjective well-being; unemployment; working population

This article in PubMed: www.ncbi.nlm.nih.gov/pubmed/26786727

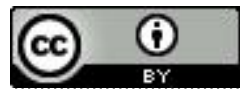




\title{
Mid-life job insecurity associated with subjective well-being in old age: results from the population-based MONICA/KORA study
}

\author{
by Amira Barrech, Diploma in Business Administration (FH), ${ }^{1}$ Jens Baumert, PhD, ${ }^{2}$ Rebecca T Emeny, \\ $\mathrm{PhD}, \mathrm{MPH},{ }^{2}$ Harald Gündel, PhD ${ }^{1}$ Karl-Heinz Ladwig, $P h D{ }^{2,3}$
}

\begin{abstract}
Barrech A, Baumert J, Emeny RT, Gündel H, Ladwig K-H. Mid-life job insecurity associated with subjective well-being in old age: results from the population-based MONICA/KORA study. Scand J Work Environ Health. 2016;42(2):170-174. first. doi:10.5271/sjweh.3546
\end{abstract}

\begin{abstract}
Objective This study aimed to examine prospectively the influence of exposure to job insecurity during working life on subjective well-being (SWB) after retirement, an association which has not been studied to date.

Method Data were derived from the prospective population-based MONICA/KORA study conducted in southern Germany. Participants were recruited and data were collected during three independent surveys between 1984-1995 (T1) and followed up in 2009 (T2). The study sample consisted of 1801 employed participants (1146 male/ 655 female) aged $41-72$ years at T1 and $\geq 65$ years at T2, without missing data. Self-administered questionnaires and clinical examinations were used to assess job insecurity and risk factors at T1 and SWB at T2. Mean follow-up was 19.6 years. Logistic regression analyses were performed to determine the association of job insecurity with SWB after retirement. We accounted for an extensive set of sociodemographic, lifestyle-, health- and work-related risk factors.
\end{abstract}

Results At T1,39.5\% of the participants reported job insecurity, which was associated with a 1.40-fold [ $95 \%$ confidence interval $(95 \% \mathrm{CI}) 1.08-1.82$ ] risk of low SWB at T2 in models adjusted for sociodemographic and lifestyle- and health-related conditions at T1. Additional adjustment for a set of work-related risk factors at T1 had little effect on this association.

Conclusions Exposure to job insecurity at midlife was associated with low SWB in retirement, even after controlling for an extensive set of risk factors. This shows that the negative effects of unstable working conditions might persist well into retirement, long after cessation of employment.

Key terms epidemiology; job stressor; risk factor; stress; unemployment; working population.

Job insecurity, ie, the anticipation of unemployment, is an occupational stressor $(1,2)$, which has been on the rise due to structural changes to the global economy $(3,4)$. While an unemployed individual can take active measures that help to cope with job loss (eg, by looking for a new job), the uncertainty inherent in job insecurity impedes preparations for the future (5). Job insecurity has been associated with somatic (6-11) and minor psychiatric morbidity $(6,12-15)$, poorer self-rated health $(8$, $12,14-16)$ and diminished subjective well-being (SWB) $(2,5,17,18)$.
SWB represents a multi-dimensional concept reflecting the positive dimensions of mental health and captures positive mood, vitality, future orientation and a general interest in life (19). It is commonly understood to represent the level of well-being people experience, based on a subjective evaluation (both cognitive and emotional) of their lives $(20,21)$. SWB has been associated with health (22) and shown to protect against negative health outcomes and mortality among older adults (23). While job insecurity has been negatively associated with SWB in the working population $(17,18)$, no study

1 Department of Psychosomatic Medicine and Psychotherapy, Universitätsklinik Ulm, Ulm, Germany.

2 Institute of Epidemiology II, Helmholtz Zentrum München, German Research Center for Environmental Health, Neuherberg, Germany.

3 Department of Psychosomatic Medicine and Psychotherapy, Klinikum rechts der Isar, Technische Universität München, Munich, Germany.

Correspondence to: Prof. Dr. K.-H. Ladwig, Institute of Epidemiology II, Helmholtz Zentrum München, German Research Center for Environmental Health, Ingolstädter Landstr. 1,85764 Neuherberg, Germany. [E-mail: ladwig@helmholtz-muenchen.de] 
has yet examined the long-term consequences of job insecurity on SWB after retirement. Therefore, the aim of this prospective study was to investigate the effect of exposure to job insecurity during working life on SWB after retirement.

\section{Methods}

\section{Setting and sample description}

Data were drawn from the representative populationbased MONICA/KORA (MONItoring trends and determinants in CArdiovascular disease/ Cooperative Health Research in the Region of Augsburg) cohort, described in detail elsewhere (24). Two data sets were available per participant: one (T1) was collected during one of three independent surveys (S1-S3) between 1984-1995, the second at follow-up (T2) in 2009 (24). Time-tofollow-up differed depending on which survey $\mathrm{T} 1$ data was derived from (S1: 24 years, S2: 19 years, S3: 14 years). The local ethics committee study approved the study, which followed the declaration of Helsinki. Each participant provided written informed consent.

Analyses were restricted to employed participants at T1 $(\mathrm{N}=7466)$, who would reach the retirement age of 65 years by $\mathrm{T} 2(\mathrm{~N}=3255)$ and without missing information on any of the study variables $(\mathrm{N}=1454)$, leading to a final study sample of $\mathrm{N}=1801$ (1146 men/ 655 women). A drop-out analysis revealed that missing information was associated with older age and male sex.

Mean age at T1 was 51.4 (SD 5.5) years and 71.0 (SD 4.7) years at T2. Mean follow-up was after 19.6 (SD 4.0) years.

\section{Measures at T1}

Job insecurity was assessed by questionnaire at $\mathrm{T} 1$ using a global single item ("Do you sometimes worry about whether you will be able to keep your current work position?), with responses scoring on a 3-point Likert scale. Participants answering "yes, frequently" or "yes, sometimes" were defined as experiencing job insecurity.

Risk factors were assessed by questionnaire or clinical examination and included the following variables: survey (S1-S3); living alone; low educational level $(<12$ years of schooling); smoking (regular consumption of $\geq 1$ cigarette/day on average); alcohol consumption (no: $0 \mathrm{~g} /$ day, moderate: $<40$ and $<20 \mathrm{~g} /$ day for men and women, respectively, high: $\geq 40$ and $20 \mathrm{~g} /$ day for men and women, respectively); obesity (body mass index $>30$ $\mathrm{kg} / \mathrm{m}^{2}$ ); physical inactivity (regular sporting activity $<1$ hour/week); and chronic diseases (history of diabetes, myocardial infarction, stroke or hypertension). Work- related risk factors included job strain (assessed by Job Content Questionnaire and computed following the manual as the ratio of job demands and job control) (25), type of work (extent of physical labor), relationship with superiors and colleagues, and adverse chronobiological conditions (overtime, shift work, night shifts, task work, assembly-line work).

\section{Measures at T2}

SWB was assessed at follow-up using the World Health Organization (WHO)-5 Well-Being Index (26) and dichotomized for reasons of comparability with other studies [eg, (17)]. Following WHO recommendations, participants with a sum score of $\leq 50$ were defined as having low $\operatorname{SWB}(19,27,28)$.

\section{Statistical analysis}

All association analyses were weighted using an inverse probability weighting approach (29) stratified for 10-year age-groups, sex, and survey to deal with missing information in the source population $(\mathrm{N}=3255)$ and robust variance estimations were computed. Mean differences were assessed by t-test, F-test, or $\chi 2$-test.

Logistic regression models were estimated to assess the association of job insecurity at T1 with low SWB at T2. Cumulative additional adjustments were made for age, sex, and survey (model 1), socio-demographic factors (model 2), life-style factors (model 3), and chronic diseases (model 4), all assessed at T1. As a sensitivity analysis, model 4 was additionally adjusted for potential work-related confounding variables. The c-statistic was used to assess the logistic model fit. All statistical analyses were performed with SAS Version 9.2 for Windows (SAS Institute, Cary, NC, USA).

\section{Results}

Out of 1801 employed participants at T1,39.5\% reported job insecurity: "yes, frequently" (4.8\%) and "yes, sometimes" (34.7\%). Job insecurity was significantly associated with younger age and lower educational level (table 1). Overall, $19.9 \%$ of the participants expressed low SWB at follow-up. Compared to participants reporting high SWB, they were significantly more likely to be older, female, less educated, current smokers, and physically inactive at $\mathrm{T} 1$ (data not shown, available from first author upon request).

Job insecurity was significantly associated with low SWB 19.6 years later in model 1 [odds ratio (OR) 1.43, 95\% confidence interval (95\% CI) 1.11-1.84; table 2]. Cumulative additional adjustments in models $2-4$ 
had little effect on this association (OR 1.40, 95\% CI $1.08-1.82$ in model 4$)$. Sensitivity analyses revealed that additional adjustments for type of work (OR 1.40, 95\% CI 1.06-1.84), relationship with supervisors (OR 1.35, 95\% CI 1.02-1.79) and colleagues (OR 1.39, 95\% CI $1.05-1.84$ ), job strain (OR 1.38, 95\% CI 1.03-1.85) and chronobiological working conditions (OR 1.43, 95\% CI 1.08-1.90) did not strongly alter the association between job insecurity and SWB (data not shown).

\section{Discussion}

To the best of our knowledge, this is the first study to provide evidence that exposure to job insecurity during

Table 1. Descriptive analyses of the association of job insecurity with sociodemographic, lifestyle and health-related variables at T1 $(\mathrm{N}=1801)$. $\mathrm{N}$ values are unweighted, $\%$ are weighted.

\begin{tabular}{|c|c|c|c|c|c|}
\hline \multirow[t]{3}{*}{ Characteristic } & \multicolumn{5}{|c|}{ Job insecurity } \\
\hline & \multicolumn{2}{|c|}{ No $(\mathrm{N}=1069)$} & \multicolumn{2}{|c|}{ Yes $(\mathrm{N}=732)$} & \multirow[t]{2}{*}{ P-value } \\
\hline & $\mathrm{N}$ & $\%$ & $\mathrm{~N}$ & $\%$ & \\
\hline Male sex & 680 & 65.4 & 466 & 64.8 & 0.777 \\
\hline Living alone & 159 & 14.3 & 132 & 17.7 & 0.057 \\
\hline Low educational level & 689 & 64.7 & 551 & 75.7 & $<0.001$ \\
\hline Smoking & 216 & 20.2 & 156 & 20.6 & 0.861 \\
\hline Alcohol consumption & & & & & 0.421 \\
\hline No & 244 & 22.0 & 160 & 21.1 & \\
\hline Moderate & 485 & 45.7 & 352 & 49.0 & \\
\hline High & 340 & 32.2 & 220 & 29.9 & \\
\hline Obesity & 194 & 18.5 & 125 & 17.6 & 0.645 \\
\hline Physical inactivity & 585 & 55.6 & 421 & 58.1 & 0.318 \\
\hline Chronic diseases a & 445 & 42.1 & 280 & 38.5 & 0.137 \\
\hline
\end{tabular}

a History of diabetes, myocardial infarction, stroke or hypertension. working life is associated with an increased risk of low SWB after retirement 20 years later, independent of well-established risk factors at T1. Our results corroborate findings from prospective studies on the active work force which have reported health-effects of job insecurity in up to 9.5 years (on average) of follow-up $(1,7$, $9,10)$. The size of the effect observed in our study was comparable to that reported in the latest cross-sectional European study on the association between job insecurity and SWB (17).

Concerning the underlying mechanisms of our findings, job insecurity is considered to be a work-related stressor which can induce physiological or mental arousal (2). Persistent exposure to job insecurity may result in an accumulation of short-term responses (eg, psychological distress, hypertension), which might lead to more permanent health outcomes in the long-term (15). Indeed, chronic exposure to job insecurity has been linked to lasting effects on health $(7,14)$. Health in turn is an important predictor of SWB in later life $(23,30)$. Personality traits may also play a role, individuals who tend to believe that they cannot influence events in their lives (external locus of control) have been shown to both experience higher job insecurity and suffer from more mental health impairments $(31,32)$.

Previous studies have also shown psychosocial and physical working conditions to be associated with impaired SWB $(17,18)$. In the present study, the association between job insecurity and SWB was marginally affected by accounting for work-related variables. In their recent cross-sectional study on the impact of psychosocial working conditions on SWB, Schütte et al (17) found similar results after using a larger number of work-related covariates in their analyses. In contrast to the present study, however, the authors did not con-

Table 2. Association of job insecurity and risk factors at T1 with the odds of low subjective well-being (SWB) at follow-up (N=1801). All models included also survey as covariate, estimates are not shown. [OR=odds ratio; $95 \% \mathrm{Cl}=95 \%$ confidence interval.]

\begin{tabular}{|c|c|c|c|c|c|c|c|c|}
\hline \multirow[t]{2}{*}{ Risk factor } & \multicolumn{2}{|c|}{ Model $1(0.59)^{\text {a }}$} & \multicolumn{2}{|c|}{ Model $2(0.59)^{\text {a }}$} & \multicolumn{2}{|c|}{ Model $3(0.63)^{\text {a }}$} & \multicolumn{2}{|c|}{ Model $4(0.63)^{\text {a }}$} \\
\hline & $\mathrm{OR}$ & $95 \% \mathrm{Cl}$ & $\mathrm{OR}$ & $95 \% \mathrm{Cl}$ & $\mathrm{OR}$ & $95 \% \mathrm{Cl}$ & $\mathrm{OR}$ & $95 \% \mathrm{Cl}$ \\
\hline Job Insecurity & 1.43 & $1.11-1.84 \mathrm{~b}$ & 1.40 & $1.08-1.81^{c}$ & 1.40 & $1.08-1.81^{c}$ & 1.40 & $1.08-1.82$ \\
\hline \multicolumn{9}{|l|}{ Sociodemographic characteristics } \\
\hline Age (per year) & 1.05 & $1.02-1.08^{b}$ & 1.05 & $1.02-1.08^{b}$ & 1.05 & $1.02-1.08^{b}$ & 1.05 & $1.02-1.07$ \\
\hline Female sex & 1.41 & $1.10-1.81^{\mathrm{b}}$ & 1.39 & $1.06-1.81^{c}$ & 1.43 & $1.08-1.89^{c}$ & 1.49 & $1.12-1.97^{b}$ \\
\hline Low educational level & & & 1.25 & $0.94-1.67$ & 1.16 & $0.87-1.56$ & 1.16 & $0.86-1.55$ \\
\hline Living alone & & & 0.90 & $0.63-1.27$ & 0.85 & $0.60-1.21$ & 0.87 & $0.61-1.24$ \\
\hline \multicolumn{9}{|l|}{ Lifestyle/clinical } \\
\hline Smoking & & & & & 1.52 & $1.13-2.05^{b}$ & 1.52 & $1.13-2.06$ \\
\hline Moderate alcohol consumption & & & & & 1.01 & $0.73-1.40$ & 1.02 & $0.74-1.41$ \\
\hline High alcohol consumption & & & & & 1.01 & $0.72-1.44$ & 1.00 & $0.71-1.42$ \\
\hline Obesity & & & & & 1.00 & $0.72-1.39$ & 0.95 & $0.68-1.32$ \\
\hline Physical inactivity & & & & & 1.59 & $1.22-2.07^{b}$ & 1.60 & $1.23-2.08$ \\
\hline History of chronic diseases ${ }^{d}$ & & & & & & & 1.31 & $1.01-1.70$ \\
\hline
\end{tabular}

${ }^{a} \mathrm{C}$ statistic (model fit)

${ }^{b} \mathrm{P}<0.05$.

c $P<0.01$.

d Diabetes, myocardial infarction, stroke or hypertension. 
trol for health-related variables. Therefore, our results further underline the significance of job insecurity as an independent risk factor to SWB in later life, over and above other potential confounders.

The strengths of our study lie in its large sample size, the availability of an extensive set of risk factors to SWB, and its long follow-up. In contrast to the majority of relevant studies $(2,17,18,33)$, we accounted for both health- and work-related risk factors. A limitation of the study lies in the single measurement of SWB at followup. Given that health is an important predictor of SWB at all ages (30), the extensive control for health-related variables in this study may partly compensate for this limitation. The single measurement of job insecurity at T1 does not allow for inferences on the length of exposure of participants. However, longitudinal evidence suggests that even short exposure to job insecurity can have long-term health-effects (7). The use of a single item is a further limitation, as they have been shown to underestimate associations between job insecurity and outcomes compared to multi-item scales (2). The predominant number of studies on the health-effects of job insecurity employ single item measures (9) and our results corroborate these findings. Finally, the assessment of job insecurity and SWB by self-report might be influenced by personality traits such as negative affectivity (34). However, there is ample evidence that job insecurity's detrimental effect on mental health is not entirely attributable to personality traits $(18,32,35)$.

\section{Concluding remarks}

Our findings underline the notion that job insecurity might be harmful to SWB in later life. Impaired health affects the elderly's quality of life and induces costs to society. It is therefore in the interest of the working population, employers and policy-makers to make a greater effort to support the workforce in dealing with job insecurity.

\section{Acknowledgements/Funding}

The MONICA/KORA Augsburg studies were initiated and funded by the GSF - National Research Centre for Environment and Health, Neuherberg, Germany (now Helmholtz Zentrum München, German Research Center for Environmental Health) and the German Federal Ministry of Education, Science, Research and Technology and by the State of Bavaria.

\section{Conflict of interest}

The authors declare no conflicts of interest.

\section{References}

1. Kinnunen U, Mäkikangas A, Mauno S, De Cuyper N, De Witte H. Development of Perceived Job Insecurity Across Two Years: Associations With Antecedents and Employee Outcomes. J Occup Health Psychol. 2014 Apr;19(2):243-58. http://dx.doi.org/10.1037/a0035835.

2. Sverke M, Hellgren J, Näswall K. No Security: A MetaAnalysis and Review of Job Insecurity and Its Consequences. J Occup Health Psychol . 2002;7(3):242-64. http://dx.doi. org/10.1037/1076-8998.7.3.242.

3. Eurofound, EU-OSHA. Psychosocial risks in Europe: Prevalence and strategies for prevention. Luxembourg: Publications Office of the European Union; 2014.

4. OECD. OECD Employment Outlook: Is Job Insecurity on the increase in OECD countries? OECD Employ Outlook. Paris; 1997.

5. De Witte H. Job Insecurity: Review of the International Literature on Definitions, Prevalence, Antecedents and Consequences. SA J Ind Psychol . 2005;31(4):1-6. http:// dx.doi.org/10.4102/sajip.v31i4.200.

6. Ferrie JE, Shipley MJ, Marmot MG, Stansfeld SA, Davey Smith $\mathrm{G}$. The health effects of major organisational change and job insecurity. Soc Sci Med . 1998;46(2):243-54. http:// dx.doi.org/10.1016/S0277-9536(97)00158-5.

7. Ferrie JE, Shipley MJ, Stansfeld SA, Marmot MG. Effects of chronic job insecurity and change in job security on self reported health, minor psychiatric morbidity, physiological measures, and health related behaviours in British civil servants: the Whitehall II study. J Epidemiol Community Health . 2002 Jun;56(6):450-4. http://dx.doi.org/10.1136/ jech.56.6.450.

8. László KD, Pikhart H, Kopp MS, Bobak M, Pajak A, Malyutina S, et al. Job insecurity and health: a study of 16 European countries. Soc Sci Med . 2010;70(6):867-74. http:// dx.doi.org/10.1016/j.socscimed.2009.11.022.

9. Virtanen M, Nyberg S, Batty G, Jokela M, Heikkila K, Fransson EI, et al. Perceived job insecurity as a risk factor for incident coronary heart disease: systematic review and metaanalysis. Br Med J . 2013;347(August):f4746. http://dx.doi. org/10.1136/bmj.f4746.

10. Ferrie JE, Kivimäki M, Shipley MJ, Davey Smith G, Virtanen M. Job insecurity and incident coronary heart disease: the Whitehall II prospective cohort study. Atherosclerosis. 2013;227(1):178-81. http://dx.doi.org/10.1016/j. atherosclerosis.2012.12.027.

11. Levenstein S, Smith MW, Kaplan GA. Psychosocial predictors of hypertension in men and women. Arch Intern Med . 2001 May;161(10):1341-6. http://dx.doi.org/10.1001/ archinte.161.10.1341.

12. Ferrie JE, Shipley MJ, Newman K, Stansfeld SA, Marmot MG. Self-reported job insecurity and health in the Whitehall II study: potential explanations of the relationship. Soc Sci Med . 2005;60(7):1593-602. http://dx.doi.org/10.1016/j. socscimed.2004.08.006. 
13. Rugulies R, Bültmann U, Aust B, Burr H. Psychosocial work environment and incidence of severe depressive symptoms: prospective findings from a 5-year follow-up of the Danish work environment cohort study. Am J Epidemiol . 2006 May 15;163(10):877-87. http://dx.doi.org/10.1093/aje/kwj119.

14. Burgard SA, Brand JE, House JS. Perceived job insecurity and worker health in the United States. Soc Sci Med 2009;69(5):777-85. http://dx.doi.org/10.1016/j. socscimed.2009.06.029.

15. Burgard SA, Kalousova L, Seefeldt KS. Perceived job insecurity and health: the Michigan Recession and Recovery Study. J Occup Environ Med . 2012 Sep;54(9):1101-6. http:// dx.doi.org/10.1097/JOM.0b013e3182677dad.

16. Rugulies R, Aust B, Burr H, Bültmann U. Job insecurity, chances on the labour market and decline in self-rated health in a representative sample of the Danish workforce. J Epidemiol Community Health . 2008 Mar;62(3):245-50. http://dx.doi. org/10.1136/jech.2006.059113.

17. Schütte S, Chastang J-F, Malard L, Parent-Thirion A, Vermeylen G, Niedhammer I. Psychosocial Working Conditions and Psychological Well-Being Among Employees in 34 European Countries. Int Arch Occup Environ Health . 2014 Nov;87(8):897-907. http://dx.doi.org/10.1007/s00420014-0930-0.

18. Kopp MS, Stauder A, Purebl G, Janszky I, Skrabski A. Work stress and mental health in a changing society. Eur J Public Health . 2008 Jun;18(3):238-44. http://dx.doi.org/10.1093/ eurpub/ckm077.

19. Bech P. Measuring the Dimension of Psychological General Well-Being by the WHO-5. Qual Life Newsl. 2004 May;(32):15-6.

20. Diener E. New Findings and Future Directions for Subjective Well-Being Research. Am Psychol. 2012;37(November):590-7. http://dx.doi.org/10.1037/a0029541.

21. Diener E, Ryan K. Subjective Well-Being: A General Overview. South African J Psychol. 2009 Dec 1;39(4):391406. http://dx.doi.org/10.1177/008124630903900402.

22. Boehm JK, Kubzansky L. The heart's content: The association between positive psychological well-being and cardiovascular health. Psychol Bull. 2012;138(4):655-91. http://dx.doi. org/10.1037/a0027448.

23. Steptoe A, Deaton A, Stone AA. Subjective wellbeing, health, and ageing. Lancet . 2014;385(9968):640-8. http://dx.doi. org/10.1016/S0140-6736(13)61489-0.

24. Holle R, Happich M, Löwel H, Wichmann H-E. KORA-A Research Platform for Population Based Health Research. Gesundheitswesen. 2005;67(Sonderheft 1):S19-25.
25. Karasek RA, Brisson C, Kawakami N, Houtman I. The Job Content Questionnaire (JCQ): an instrument for internationally comparative assessments of psychosocial job characteristics. J Occup Health Psychol. 1998;3(4):322-55. http://dx.doi. org/10.1037/1076-8998.3.4.322.

26. Bonsignore M, Barkow K, Jessen F, Heun R. Validity of the five-item WHO Well-Being Index (WHO-5) in an elderly population. Eur Arch Psychiatry Clin Neurosci. 2001 Jan;251(Suppl 2):II/27 - II/31.

27. Topp CW, Østergaard SD, Søndergaard S, Bech P. The WHO5 well-being index: A systematic review of the literature. Psychother Psychosom. 2015;84(3):167-76. http://dx.doi. org/10.1159/000376585.

28. World Health Organisation. Wellbeing Measures in Primary Health Care/ The Depcare Project. Rep a WHO Meet. Copenhagen; 1998.

29. Seaman SR, White IR. Review of inverse probability weighting for dealing with missing data. Stat Methods Med Res. 2013;22:278-95. http://dx.doi. org/10.1177/0962280210395740.

30. George LK. Still Happy After All These Years : Research Frontiers on Subjective Well-being in Later Life. Journals Gerontol Ser B-Psychological Sci Soc Sci. 2010;65(3):331-9. http://dx.doi.org/10.1093/geronb/gbq006.

31. Keim A, Landis R, Pierce C, Earnest D. Why Do Employees Worry About Their Jobs? A Meta-Analytic Review of Predictors of Job Insecurity. J Occup Health Psychol. 2014;19(3):269-90. http://dx.doi.org/10.1037/a0036743.

32. Näswall K, Sverke M, Hellgren J. The moderating role of personality characteristics on the relationship between job insecurity and strain. Work Stress. 2005 Jan;19(1):37-49. http://dx.doi.org/10.1080/02678370500057850.

33. Cheng GH-L, Chan DK-S. Who Suffers More from Job Insecurity? A Meta-Analytic Review. Appl Psychol. 2008 Apr;57(2):272-303. http://dx.doi.org/10.1111/j.14640597.2007.00312.x.

34. Sverke M, Hellgren J. The Nature of Job Insecurity: Understanding Employment Uncertainty on the Brink of a New Millennium. Appl Psychol. 2002 Jan;51(1):23-42. http:// dx.doi.org/10.1111/1464-0597.0077z.

35. Stansfeld SA, Candy B. Psychosocial work environment and mental health--a meta-analytic review. Scand J Work Environ Health. 2006;32(6):443-62. http://dx.doi.org/10.5271/ sjweh. 1050 .

Received for publication: 19 June 2015 